\section{RMD Open}

Rheumatic \& Musculoskeletal Diseases

\title{
Design and rationale of the Study of Etanercept and Methotrexate in Combination or as Monotherapy in Subjects with Psoriatic Arthritis (SEAM-PsA)
}

\author{
Philip J Mease, ${ }^{1}$ Dafna D Gladman, ${ }^{2}$ Ahmed S Samad, ${ }^{3}$ Laura C Coates, ${ }^{4}$ \\ Lyrica X H Liu, ${ }^{5}$ Girish A Aras, ${ }^{5}$ David H Collier, ${ }^{3}$ James B Chung $^{3}$
}

\begin{abstract}
To cite: Mease PJ, Gladman DD, Samad AS, et al. Design and rationale of the Study of Etanercept and Methotrexate in Combination or as Monotherapy in Subjects with Psoriatic Arthritis (SEAM-PSA). RMD Open 2017;4:e000606. doi:10.1136/ rmdopen-2017-000606

- Prepublication history for this paper is available online. To view these files, please visit the journal online (http://dx.doi. org/10.1136/rmdopen-2017000606).
\end{abstract}

Received 25 October 2017 Revised 14 December 2017 Accepted 19 December 2017

\section{Check for updates}

${ }^{1}$ Rheumatology Clinical Research Division, Swedish Medical Center and Division of Rheumatology, University of Washington, Seattle, Washington, USA

${ }^{2}$ Department of Medicine, University of Toronto, Toronto, Ontario, Canada

${ }^{3}$ US Medical Organization, Amgen Inc., Thousand Oaks, CA, USA

${ }^{4}$ Nuffield Department of Orthopaedics, Rheumatology and Musculoskeletal Sciences, University of Oxford, Oxford, UK ${ }^{5}$ Global Biostatistical Science, Amgen Inc., Thousand Oaks, CA, USA

Correspondence to Professor Philip J Mease; pmease@philipmease.com

\section{ABSTRACT}

Objective To evaluate the efficacy of etanercept and methotrexate as monotherapies and as combination therapy in subjects with active psoriatic arthritis (PsA). Methods The Study of Etanercept and Methotrexate in Combination or as Monotherapy in Subjects with Psoriatic Arthritis (SEAM-PSA) is an ongoing, global, doubleblind, 48-week, randomised, controlled study. Subjects are randomised (1:1:1) to etanercept monotherapy, methotrexate monotherapy or etanercept-methotrexate combination therapy. Endpoints include rates of ACR20 response and Minimal Disease Activity, measures to characterise extra-articular manifestations (dactylitis, enthesitis, nail disease) and safety.

Conclusion SEAM-PSA will characterise the effects of etanercept with and without background methotrexate and methotrexate alone on PsA manifestations, and provide information of practical importance to clinicians on the optimal treatment of PsA.

\section{INTRODUCTION}

Psoriatic arthritis (PsA) is a chronic inflammatory disease of the peripheral joints and axial skeleton with an estimated prevalence of $0.06 \%-0.25 \%$ in the US general population, and of $6 \%-41 \%$ in patients with psoriasis. ${ }^{1}$ The clinical features of PsA are heterogeneous and include peripheral arthritis, axial disease, dactylitis, enthesitis, and skin and nail disease. ${ }^{2}$ Despite long-term availability of tumour necrosis factor inhibitors (TNFi) for treatment of PsA, their optimal use as monotherapy or combination therapy with methotrexate has not been established. Additionally, most patients with PsA who have participated in clinical trials have established disease, and an understanding of how effective treatment early in the disease course may impact longterm outcomes is lacking.

\section{Key messages}

What is already known about this subject?

- Based on practices in treating patients with rheumatoid arthritis, combination therapy with the tumour necrosis factor inhibitor etanercept and methotrexate is common in patients with psoriatic arthritis (PsA), even though methotrexate is not approved for the treatment of PSA.

What does this study add?

- The Study of Etanercept and Methotrexate in Combination or as Monotherapy in Subjects with Psoriatic Arthritis (SEAM-PSA) aims to examine the efficacy of etanercept or methotrexate as monotherapy and in combination in patients with PsA.

How might this impact on clinical practice?

- The results of SEAM-PSA are expected to inform clinicians about the comparative efficacy of these therapies and provide guidance on the optimal treatment of PSA.

In general, PsA is treated initially with conventional synthetic disease-modifying antirheumatic drugs (csDMARD), followed most commonly by the use of biological DMARDs (bDMARDs), including TNFi and interleukin (IL)-12/23 or IL-17 blockers. Methotrexate is the most common first-line csDMARD for PsA and is included in all treatment guidelines for PsA; however, methotrexate is not an approved drug for the treatment of PsA in the USA and in many other countries, nor is there substantive evidence for its efficacy in randomised clinical trials. ${ }^{34}$ Furthermore, physicians and patients have concerns about the use of methotrexate because of side effects and required lifestyle modifications. As a result, patients with PsA may 


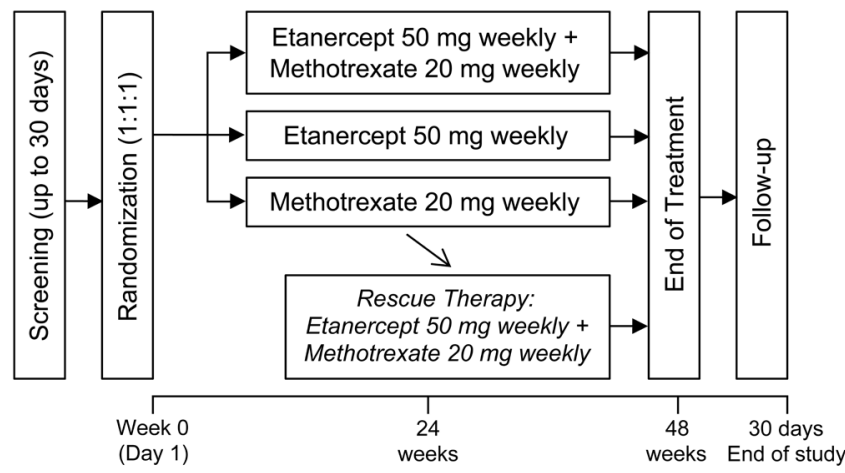

Figure 1 Study schema.

prefer bDMARD monotherapy rather than methotrexate monotherapy or combination therapy with bDMARDs.

In the Methotrexate in Psoriatic Arthritis (MIPA) study, methotrexate-naïve subjects received methotrexate $\left(15 \mathrm{mg} /\right.$ week) or placebo for 6 months. ${ }^{3}$ In an intent-totreat analysis, no statistically significant improvements in disease activity measures at 24 weeks were observed except for the Psoriatic Arthritis Response Criteria, although the rate of 20\% improvement in American College of Rheumatology criteria (ACR20 response) was numerically higher for methotrexate than placebo and there was a suggestion of efficacy in a subgroup of subjects with polyarticular disease. A key limitation of the study was that a submaximal dose $(15 \mathrm{mg})$ was used. In contrast, TNFi have been shown to be effective agents in PsA, improving joint symptoms and inhibiting the progression of structural damage. ${ }^{5}$ They also improve cutaneous and other extra-articular manifestations of PsA. ${ }^{5}$ In TNFi clinical trials, the presence or absence of methotrexate background therapy did not appear to affect outcomes, but most patients previously had an inadequate response to methotrexate, so these results did not truly address the utility of methotrexate background therapy. ${ }^{6}$

Registry studies have shown no consistent difference in response between patients who started a TNFi with or without methotrexate, ${ }^{78}$ but differences in survival (ie, the rate that a cohort discontinued use of an agent) appeared when analysing specific agents, suggesting longer survival when etanercept was used as monotherapy compared with infliximab. One contribution to this difference may be differences in immunogenicity with different agents. ${ }^{9}$ These results suggested that the combination therapy used in rheumatoid arthritis (RA) to provide superior efficacy to methotrexate or etanercept monotherapy may not have a similar impact on efficacy in PsA. ${ }^{10}$ Therefore, a gap exists in our understanding of the true effect of methotrexate monotherapy in PsA and the additional benefit of combining methotrexate with TNFi on which to base sound recommendations to patients.

\section{METHODS}

The Study of Etanercept and Methotrexate in Combination or as Monotherapy in Subjects with Psoriatic Arthritis (SEAM-PsA) aims to address these key questions.
SEAM-PsA (ClinicalTrials.gov number NCT02376790) is a global, double-blind, randomised, controlled study that is currently enrolling adult subjects with active PsA with both skin and joint symptoms who are bDMARD naïve and methotrexate naive.

The study comprises a 48-week treatment period and 30-day follow-up period (figure 1). Subjects are randomised to one of three arms ( $\mathrm{n}=280$ subjects per arm): etanercept $50 \mathrm{mg}$ weekly administered subcutaneously plus methotrexate $20 \mathrm{mg}$ weekly administered orally; etanercept $50 \mathrm{mg}$ weekly subcutaneously plus oral placebo; or oral methotrexate $20 \mathrm{mg}$ weekly plus subcutaneous placebo. At or after week 24, subjects with inadequate response receive rescue therapy with etanercept plus methotrexate.

The primary endpoint is the ACR20 response at week 24 and the key secondary endpoint is the Minimal Disease Activity (MDA) response at week 24. Other secondary endpoints include measures to characterise extra-articular manifestations in nails (modified Nail Psoriasis Severity Index (NAPSI)), dactylitis (Leeds dactylitis score), enthesitis (Spondyloarthritis Research Consortium of Canada (SPARCC) enthesitis score), composite measures shared with RA (Disease Activity Score based on 28 joints, Simplified Disease Activity Index, Clinical Disease Activity Index) and those specific to PsA (Psoriatic Arthritis Disease Activity Score), and safety (table 1). For those with psoriasis with affected baseline body surface area (BSA) $\geq 3 \%$, static physician global assessment and BSA will be assessed. Patient-reported measures of Health Assessment Questionnaire Disability Index and Short-Form 36 at week 24 are also secondary endpoints. Measures of radiographic progression are included as exploratory endpoints, including the change from baseline and non-progression in the van der Heijde modified Total Sharp Score (mTSS) at weeks 24 and 48.

The design and sample size of SEAM-PsA were informed by four key studies of methotrexate and/or etanercept for PsA (table 2). There are no published studies of etanercept monotherapy compared with methotrexate monotherapy for the treatment of PsA. Therefore, assumed response rates are derived from separate studies. In the pivotal trial of etanercept for the treatment of PsA, the proportions of subjects with ACR20 responses were $50 \%$ in the etanercept arm and $14 \%$ in the placebo arm at week $24 .{ }^{6}{ }^{11}$ Assuming the etanercept response in a methotrexate-naïve population would be better, a $60 \%$ response rate for the etanercept monotherapy arm is assumed. The MIPA trial showed an ACR20 response of $34 \%$ with methotrexate, although the dose used was suboptimal. ${ }^{3}$ Efficacy of methotrexate monotherapy based on ACR20 responses at 6 months was estimated to be $44 \%$ for SEAM-PsA, to account for the higher dose of methotrexate $(20 \mathrm{mg} /$ week) employed in this trial. The ACR20 response rate at week 24 for etanercept plus methotrexate combination therapy is assumed to be $5 \%$ higher than that for etanercept monotherapy (ie, 
Table 1 Outcome measures

\begin{tabular}{ll}
\hline Outcome measures & Definition/description \\
\hline Primary outcome measure & $\begin{array}{l}20 \% \text { improvement in American College of Rheumatology response criteria; } \\
\text { composite measure based on tender and swollen joint counts, patient's assessment } \\
\text { of pain, patient and physician global assessment of disease activity, patient's } \\
\text { assessment of physical function and acute-phase reactant value }\end{array}$ \\
\hline
\end{tabular}

\begin{tabular}{|c|c|}
\hline \multicolumn{2}{|l|}{ Secondary outcomes } \\
\hline \multicolumn{2}{|c|}{ Composite measures of disease activity } \\
\hline MDA & $\begin{array}{l}\text { Minimal Disease Activity; composite measure based on tender and swollen joint } \\
\text { counts, Psoriasis Area and Severity Index or psoriasis-affected BSA; patient pain, } \\
\text { patient global activity, HAQ and tender entheseal points }\end{array}$ \\
\hline PASDAS & $\begin{array}{l}\text { Psoriatic Arthritis Disease Activity Score; composite measure based on patient } \\
\text { and physician assessments of disease activity, peripheral joint counts, dactylitis, } \\
\text { enthesitis, acute-phase reactant value and SF-36 physical component score }\end{array}$ \\
\hline DAS28 & $\begin{array}{l}\text { Disease Activity Score based on } 28 \text { joints; based on tender and swollen joint counts, } \\
\text { patient assessment of general health and an acute-phase reactant value }\end{array}$ \\
\hline SDAl & $\begin{array}{l}\text { Simplified Disease Activity Index; based on swollen and tender joint counts, acute- } \\
\text { phase reactant value, and patient and physician assessments of disease activity }\end{array}$ \\
\hline CDAl & $\begin{array}{l}\text { Clinical Disease Activity Index; based on swollen and tender joint counts, and patient } \\
\text { and physician assessments of disease activity }\end{array}$ \\
\hline Leeds dactylitis score & Based on circumference and tenderness of affected digits \\
\hline SPARCC & $\begin{array}{l}\text { Spondyloarthritis Research Consortium of Canada; measures tenderness in } 16 \\
\text { entheseal sites }\end{array}$ \\
\hline NAPSI & Nail Psoriasis Severity Index; based on psoriasis in nail bed and matrix \\
\hline BSA & Psoriasis-affected body surface area reported as a percentage \\
\hline sPGA & $\begin{array}{l}\text { Static physician global assessment; based on the severity of induration, erythema } \\
\text { and scaling of psoriasis lesions }\end{array}$ \\
\hline \multicolumn{2}{|c|}{ Patient-reported outcomes } \\
\hline HAQ-DI & $\begin{array}{l}\text { Health Assessment Questionnaire Disability Index; based on patient difficulties with } \\
\text { eight quality-of-life categories }\end{array}$ \\
\hline
\end{tabular}

$65 \%$ ) based on longitudinal observational studies assessing the role of TNFi and methotrexate combination therapy compared with TNFi monotherapy. ${ }^{78}$
SEAM-PsA is powered to detect a treatment difference in ACR20 response at week 24 between the etanercept plus methotrexate therapy arm and the methotrexate

Table 2 Key studies and observations used in the design of SEAM-PsA

\section{Study (Reference)}

Methotrexate in Psoriatic Arthritis (MIPA) ${ }^{3}$

Etanercept PsA pivotal phase 3 study $^{611}$

Norwegian Disease-modifying Antirheumatic Drugs Longitudinal Observational Study (NOR-DMARD) ${ }^{7}$ Corrona registry ${ }^{8}$

\section{Observation}

Methotrexate monotherapy at $15 \mathrm{mg} /$ week did not result in statistically significant improvements compared with placebo

Similar efficacy was demonstrated between etanercept monotherapy and combination therapy with etanercept plus methotrexate Combination therapies that are efficacious in patients with RA do not provide similar efficacy in patients with PsA

PsA, psoriatic arthritis; RA, rheumatoid arthritis; SEAM-PsA, Study of Etanercept and Methotrexate in Combination or as Monotherapy in

Subjects with Psoriatic Arthritis. 
monotherapy arm at a two-sided 0.025 significance level with $>90 \%$ power.

\section{DISCUSSION}

The SEAM-PsA trial will address clinically important questions about the relative efficacy of methotrexate and etanercept and the combination using ACR20 as well as the MDA, representing a target level of disease activity. It will help address the management of treatment-naïve patients and provide data on a broad range of clinical outcomes associated with PsA. The study has been designed to evaluate efficacy of etanercept and/or methotrexate only; generalisability of the results to other TNFi bDMARDs must take into account the unique profiles of each agent, including the impact of immunogenicity.

There is a need for standardisation of measures to determine disease severity. SEAM-PsA will evaluate response to treatment based on the proportion of subjects achieving an ACR20 response (which is essentially a minimally important response) and MDA, a disease activity state that has been recently developed and validated for PsA that represents a significant response. ${ }^{12} 13$ MDA criteria provide a useful target for treat-to-target treatment strategies, and incorporate measures of joint and entheseal inflammation, skin disease, patient-reported outcomes and functional disability. Results from the TICOPA study $^{14}$ and observational studies ${ }^{15-17}$ showed that MDA is achieved at most by $25 \%$ of patients treated with methotrexate, whereas patients treated with a TNFi achieved MDA at a frequency $>60 \%$. Post hoc analyses may include rates of very low disease activity, in which all seven conditions of MDA must be met.

This study will also characterise the response rates of etanercept and methotrexate as monotherapy or combination therapy for enthesitis, dactylitis and psoriatic nail changes. There is currently a paucity of data regarding the efficacy of methotrexate monotherapy for dactylitis and enthesitis in patients with PsA. A recent study showed that etanercept $50 \mathrm{mg}$ weekly led to $72 \%$ improvement in NAPSI score. ${ }^{18}$ Another study showed that methotrexate monotherapy improved NAPSI score by $54 \%$ at 24 weeks. $^{19}$ Measures to assess enthesitis in SEAM-PsA include the SPARCG and the Leeds Enthesitis Index; dactylitis will be measured using the Leeds dactylitis score. $^{20}$

The ability of a therapeutic agent to improve the signs and symptoms of PsA must be placed in the context of disease modification. Treatment with methotrexate has not been shown to affect radiographic progression in patients with PsA, ${ }^{14}$ whereas TNFi have consistently demonstrated improved radiographic outcomes. ${ }^{21}$ SEAM-PsA presents the opportunity to more precisely characterise the impact of methotrexate alone on radiographic progression relative to a TNFi. Radiographic progression is measured using the van der Heijde mTSS for PsA (exploratory endpoint). To maximise the ability to detect a potential difference in the radiographic outcome measure between treatment arms, blinding was extended through 48 weeks.

In summary, SEAM-PsA will provide information on the potential role of methotrexate and etanercept as monotherapy in the treatment of PsA, and whether the combination of TNFi and methotrexate confers additional short-term benefits to TNFi alone. The results will provide guidance of great practical value for patients and their physicians.

Acknowledgements Julie Wang (Amgen) and Julia R Gage (on behalf of Amgen) assisted with writing the manuscript.

Contributors PJM, ASS, DHC and JBC contributed to the conception and design of the study, analysis and interpretation of data, and revision of the manuscript. DDG, LCC, LXHL and GAA contributed to the analysis and interpretation of data and revision of the manuscript. All authors approved the final draft of the manuscript for publication.

Funding This study was sponsored by Amgen.

Competing interests PJM has received research grants, served as a consultant, and/or participated as a speaker for AbbVie, Amgen, Bristol-Myers Squibb, Celgene, Genentech, Janssen Global Services, Eli Lilly, Merck Sharp \& Dohme, Novartis, Pfizer, Sun Pharma, UCB, and Zynerba Pharmaceuticals. DDG has received research funding from and/or been a consultant to AbbVie, Amgen, Bristol-Myers Squibb, Celgene, Eli Lilly, Janssen Global Services, Novartis, Pfizer, and UCB. ASS, LXHL, GAA, DHC and JBC are employees and shareholders of Amgen. LCC has received research funding from and/or been a consultant for AbbVie, Amgen, Celgene, Janssen Global Services, Eli Lilly, Merck Sharp \& Dohme, Novartis, Pfizer, Sun Pharma, and UCB.

Ethics approval Institutional Review Board approval is obtained from each study site.

Provenance and peer review Not commissioned; externally peer reviewed. Data sharing statement The study is ongoing and is not available.

Open Access This is an Open Access article distributed in accordance with the Creative Commons Attribution Non Commercial (CC BY-NC 4.0) license, which permits others to distribute, remix, adapt, build upon this work non-commercially, and license their derivative works on different terms, provided the original work is properly cited and the use is non-commercial. See: http://creativecommons.org/ licenses/by-nc/4.0/

(C) Article author(s) (or their employer(s) unless otherwise stated in the text of the article) 2017. All rights reserved. No commercial use is permitted unless otherwise expressly granted.

\section{REFERENCES}

1. Ogdie A, Weiss P. The epidemiology of psoriatic arthritis. Rheum Dis Clin North Am 2015;41:545-68.

2. Gladman DD. Clinical features and diagnostic considerations in psoriatic arthritis. Rheum Dis Clin North Am 2015;41:569-79.

3. Kingsley GH, Kowalczyk A, Taylor $\mathrm{H}$, et al. A randomized placebocontrolled trial of methotrexate in psoriatic arthritis. Rheumatology 2012;51:1368-77.

4. Mease PJ. Spondyloarthritis: Is methotrexate effective in psoriatic arthritis? Nat Rev Rheumatol 2012;8:251-2.

5. D'Angelo S, Tramontano G, Gilio M, et al. Review of the treatment of psoriatic arthritis with biological agents: choice of drug for initial therapy and switch therapy for non-responders. Open Access Rheumatol 2017;9:21-8.

6. Mease PJ, Goffe BS, Metz J, et al. Etanercept in the treatment of psoriatic arthritis and psoriasis: a randomised trial. Lancet 2000;356:385-90.

7. Fagerli KM, Lie E, van der Heijde D, et al. The role of methotrexate co-medication in TNF-inhibitor treatment in patients with psoriatic arthritis: results from 440 patients included in the NOR-DMARD study. Ann Rheum Dis 2014;73:132-7.

8. Mease PJ, Collier DH, Saunders KC, et al. Comparative effectiveness of biologic monotherapy versus combination therapy for patients with psoriatic arthritis: results from the Corrona registry. RMD Open 2015;1:e000181.

9. Thomas SS, Borazan N, Barroso N, et al. Comparative immunogenicity of TNF inhibitors: impact on clinical efficacy 
and tolerability in the management of autoimmune diseases. A systematic review and meta-analysis. BioDrugs 2015;29:241-58.

10. Klareskog L, van der Heijde D, de Jager JP, et al. Therapeutic effect of the combination of etanercept and methotrexate compared with each treatment alone in patients with rheumatoid arthritis: doubleblind randomised controlled trial. Lancet 2004;363:675-81.

11. Mease PJ, Kivitz AJ, Burch FX, et al. Etanercept treatment of psoriatic arthritis: safety, efficacy, and effect on disease progression. Arthritis Rheum 2004;50:2264-72.

12. Coates LC, Fransen J, Helliwell PS. Defining minimal disease activity in psoriatic arthritis: a proposed objective target for treatment. Ann Rheum Dis 2010;69:48-53.

13. Coates LC, Helliwell PS. Validation of minimal disease activity criteria for psoriatic arthritis using interventional trial data. Arthritis Care Res 2010;62:965-9.

14. Coates LC, Moverley AR, McParland L, et al. Effect of tight control of inflammation in early psoriatic arthritis (TICOPA): a UK multicentre, open-label, randomised controlled trial. Lancet 2015;386:2489-98.

15. Sheane BJ, Thavaneswaran A, Gladman DD, et al. Attainment of minimal disease activity using methotrexate in psoriatic arthritis. $J$ Rheumatol 2016;43:1718-23.

16. Coates LC, Cook R, Lee KA, et al. Frequency, predictors, and prognosis of sustained minimal disease activity in an observational psoriatic arthritis cohort. Arthritis Care Res 2010;62:970-6.

17. Haddad A, Thavaneswaran A, Ruiz-Arruza l, et al. Minimal disease activity and anti-tumor necrosis factor therapy in psoriatic arthritis. Arthritis Care Res 2015;67:842-7.
18. Ortonne JP, Paul C, Berardesca E, et al. A 24-week randomized clinical trial investigating the efficacy and safety of two doses of etanercept in nail psoriasis. Br J Dermatol 2013;168:1080-7.

19. Gümüșel M, Özdemir M, Mevlitoğlu I, et al. Evaluation of the efficacy of methotrexate and cyclosporine therapies on psoriatic nails: a one-blind, randomized study. J Eur Acad Dermatol Venereol 2011;25:1080-4.

20. Mease PJ. Measures of psoriatic arthritis: Tender and Swollen Joint Assessment, Psoriasis Area and Severity Index (PASI), Nail Psoriasis Severity Index (NAPSI), Modified Nail Psoriasis Severity Index (mNAPSI), Mander/Newcastle Enthesitis Index (MEI), Leeds Enthesitis Index (LEI), Spondyloarthritis Research Consortium of Canada (SPARCC), Maastricht Ankylosing Spondylitis Enthesis Score (MASES), Leeds Dactylitis Index (LDI), Patient Global for Psoriatic Arthritis, Dermatology Life Quality Index (DLQI), Psoriatic Arthritis Quality of Life (PsAQOL), Functional Assessment of Chronic Illness Therapy-Fatigue (FACIT-F), Psoriatic Arthritis Response Criteria (PsARC), Psoriatic Arthritis Joint Activity Index (PsAJAl), Disease Activity in Psoriatic Arthritis (DAPSA), and Composite Psoriatic Disease Activity Index (CPDAl). Arthritis Care Res 2011;63 (Suppl 11):S64-85.

21. Eder L, Thavaneswaran A, Chandran V, et al. Tumour necrosis factor $\alpha$ blockers are more effective than methotrexate in the inhibition of radiographic joint damage progression among patients with psoriatic arthritis. Ann Rheum Dis 2014;73:1007-11. 